\title{
Toward a cross-border early-warning system for Central Asia
}

\author{
Jacek Stankiewicz ${ }^{1, \star}$, Dino Bindi ${ }^{2}$, Adrien Oth $^{1}$, Stefano Parolai ${ }^{2}$ \\ ${ }^{1}$ European Center for Geodynamics and Seismology, Walferdange, Luxembourg \\ ${ }^{2}$ Helmholtz Center Potsdam - German Research Center for Geosciences, Potsdam, Germany
}

\author{
Article history \\ Received September 19, 2014; accepted November 20, 2014. \\ Subject classification: \\ Seismic risk, Earthquake early warning, Central Asia.
}

\begin{abstract}
Rapidly expanding urban areas in Central Asia are increasingly vulnerable to seismic risk; but at present, no earthquake early warning (EEW) systems exist in the region despite their successful implementation in other earthquake-prone areas. Such systems aim to provide short (seconds to tens of seconds) warnings of impending disaster, enabling the first risk mitigation and damage control steps to be taken. This study presents the feasibility of a large scale cross-border regional system for Central Asian countries. Genetic algorithms are used to design efficient EEW networks, computing optimal station locations and trigger thresholds in recorded ground acceleration. Installation of such systems within 3 years aims to both reducing the endemic lack of strong motion data in Central Asia that is limiting the possibility of improving seismic hazard assessment, and at providing the first regional earthquake early warning system in the area.
\end{abstract}

\section{Introduction}

Proximity of many large global cities (e.g. Tokyo, Istanbul) to seismically active regions, and the associated earthquake risk, has led to the development of Earthquake Early Warning (EEW) systems. Such systems aim to provide a warning to the target city after an earthquake has occurred, but before the potentially destructive seismic waves arrive [Satriano et al. 2011, and references therein]. In this time, typically of the order of seconds to tens of seconds, several damage controls steps can be taken. These can include orderly suspension of activities in hospitals or shut downs of power supply [Allen et al. 2009, Nakamura et al. 2011].

That Central Asia is exposed to seismic risk is well documented [e.g. Abdrakhmatov et al. 2003, Torizin et al. 2009]. Recent studies have shown how recent urbanization has made the big cities of the region especially vulnerable to natural disasters [Bindi et al. 2011a, Pilz et al. 2013]. Despite that, no EEW systems exist in the region, even though feasibility studies showing how such networks could perform have been presented [e.g. Pi- cozzi et al. 2013, Stankiewicz et al. 2013]. This study further demonstrates the benefits such systems would bring the region, addressing concepts ranging from logistics of deploying the system to optimizing its performance.

\section{Ground acceleration based systems}

The EEW systems presented in this study follow the concept developed by Oth et al. [2010] for evaluating and improving the system in Istanbul. The approach has also been used in feasibility studies for such systems in Central Asia [Stankiewicz et al. 2013, Pittore et al. 2014], and thus only an overview of the concept will be given here. An important feature of a successful EEW system is the ability to provide not just timely, but also accurate warnings. Here, as in the studies mentioned above, the ground shaking expected at the target city is expressed via different warning classes. Four such classes are defined, with values of the peak ground acceleration (PGA) at the target used to separate them. Class 0 events, for which no warning is deemed necessary, are those where the PGA does not exceed $0.02 \mathrm{~g}$. Class I events are defined as those not exceeding $0.07 \mathrm{~g}$, with $0.12 \mathrm{~g}$ the value separating classes II and III.

For any hypothetical network, as well as defining the locations of the stations to constitute the system, three ground acceleration thresholds need to be defined. While the network operates, when during a $5 \mathrm{~s}$ time frame a given trigger threshold is exceeded at any three stations, a warning at the associated class will be issued. While these thresholds correspond to the warning classes, their values do not necessarily match the class boundaries. A network of $\mathrm{n}$ stations is thus defined by $n+3$ degrees of freedom.

To evaluate the performance of a hypothetical network, a number of scenario events needs to be considered. These should be a representative sample of the 


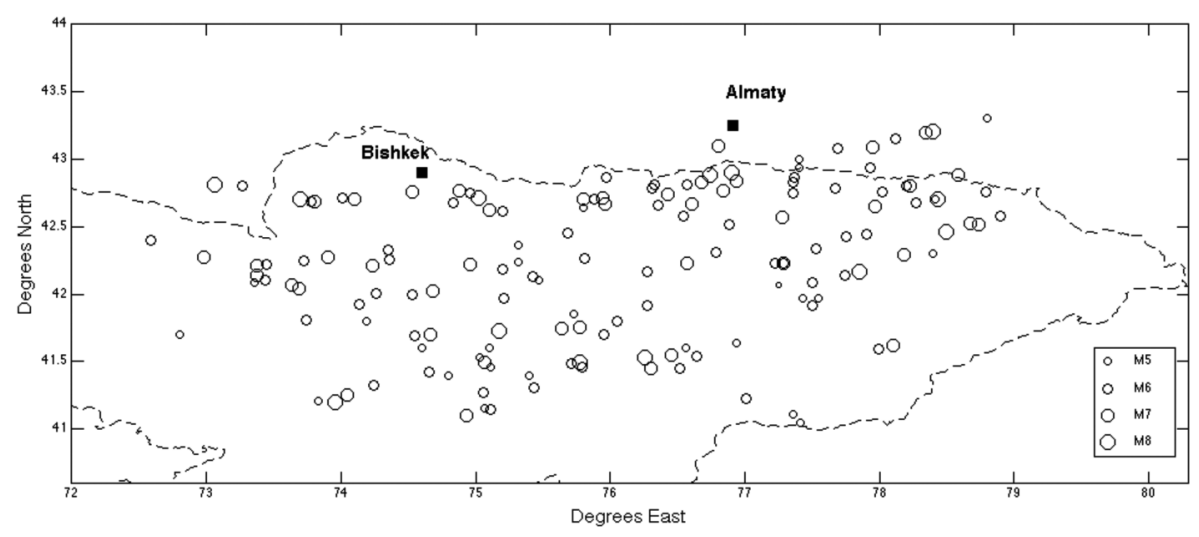

Figure 1. Location of 150 scenario earthquakes potentially threatening Bishkek and Almaty considered in the study.

earthquakes likely to threaten the target. For each scenario the cost function is then computed. This is a value between 0 and 1 . An incorrect level of warning automatically leads to the cost being 1 . For correct warnings, the lead time between the warning and the class defining acceleration being experienced is the key parameter. As the time increases over 10 seconds, the cost tends to 0 , while it tends to 1 for short warning times. The exact definition can be adjusted according to the requirements of the end users of the system, such as authorities in the target city (see Oth et al. [2010], for discussion). The cost function of the network is then the weighted average of individual scenario costs.

To minimize the cost function, and thus identify the most efficient EEW systems, microgenetic algorithms were used [Krishnakumar 1989]. These guided search techniques are based on evolutionary principles. Starting with a random population (of networks, in our case), information is exchanged between the fittest members (those with lowest cost function values) to produce the next generation of the population. This is done iteratively until satisfactory convergence. Due to randomness being present in the process, it needs to be performed repeatedly, with different starting values. It is important to note that the end result is not a single network configuration, but many (hundreds, or thousands) of potential networks with similar cost values. To these further criteria, such as accessibility for maintenance, or reliability of wireless signal, can be applied before a particular network is chosen for deployment.

The evaluation process discussed above requires recordings of seismic traces from each scenario not only at the target site, but also at every prospective station location. Due to the sparsity of recordings in Central Asia, as well as considering the deployment of new stations, such a complete database is not available. For this reason stochastic simulations of scenario events were calculated using the finite-source ground motion simulator EXSIM [Boore 2009].

\section{Target cities in Central Asia}

In this study we first consider the cities of Bishkek (Kyrgyzstan) and Almaty (Kazakhstan) as targets needing warning systems. Their proximity to each other leads to do define a common set of 150 scenario events for them (Figure 1). These scenarios include 108 events randomly generated along active tectonic features, 28 locations of major historical events in the region [Kalmetieva et al. 2009, Bindi et al. 2011b], and 14 random events whose magnitude does not exceed 5.5. For each scenario, synthetic seismic traces were computed for both cities, as well as for 256 hypothetical station locations located on a $0.2^{\circ}$ spaced grid between $41.6^{\circ}$ and $43^{\circ}$ north, and $72.8^{\circ}$ and $79^{\circ}$ east.

Given the proximity of Bishkek and Almaty, the question arises whether a single warning system for two cities would be feasible. This would significantly reduce the (monetary) cost and effort associated with system deployment and maintenance. To investigate this, for every hypothetical network the cost function for each city is calculated, and the two values are added together as a total cost. The optimization process then attempts to minimize this total value. All networks in this process have two sets of ground acceleration thresholds, one for each target (though nothing is stopping the two sets from being identical, if that turns out to be most efficient). The networks in this step thus have $\mathrm{n}+6$ degrees of freedom.

\section{Results}

Using the techniques outlined above (and discussed in detail by Oth et al. [2010]), a warning time of $10 \mathrm{sec}-$ onds was aimed for. For each specified number of stations to make up a warning system, hundreds of possible efficient network configurations were computed for each city using 10 independent runs of the optimization process (this is necessary due to the randomness present in the algorithm). As an example, the most efficient system for Bishkek made up of 8 stations is presented in Fig- 

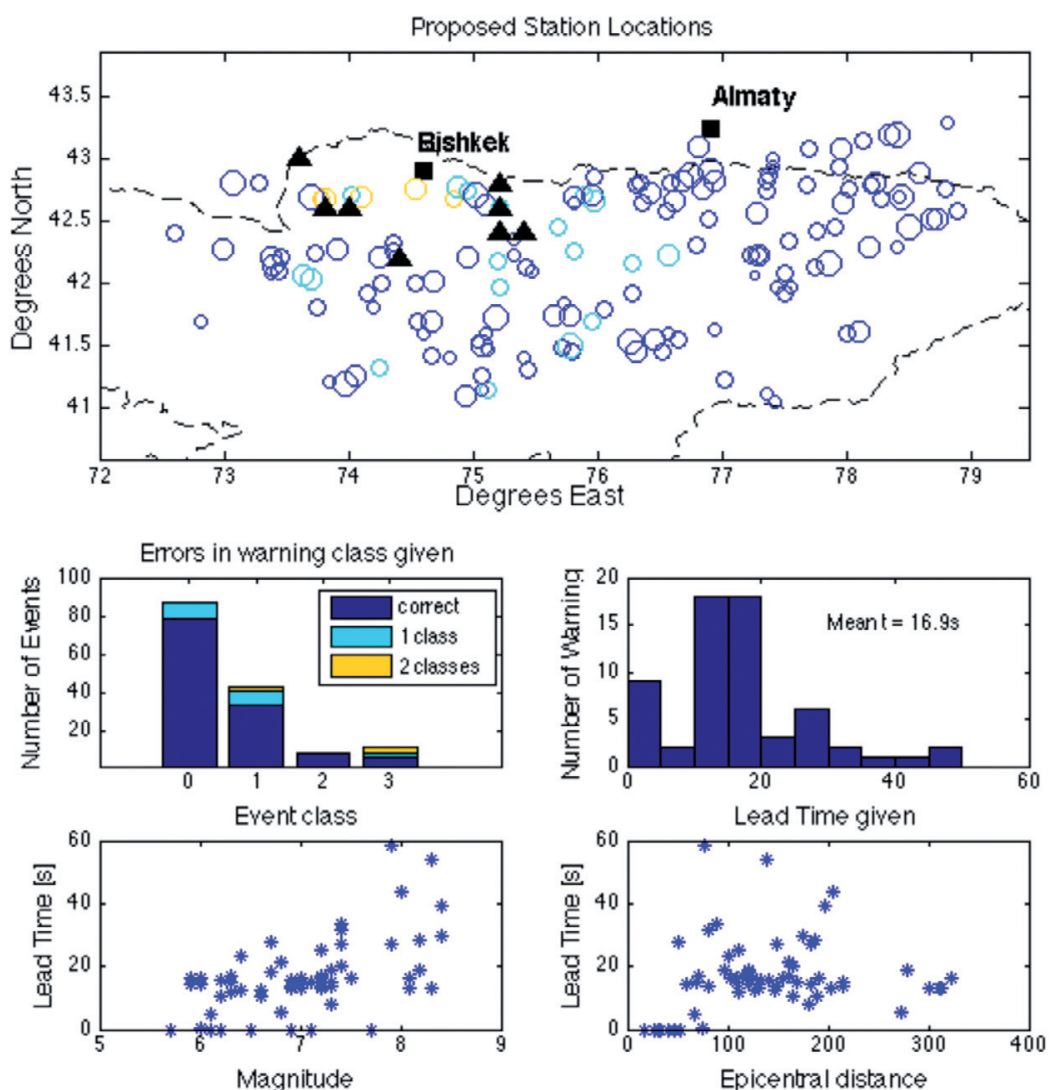

Figure 2. Most efficient 8 station warning system for Bishkek. Top panel: Location of stations (black triangles) on the outline of Kyrgyzstan and scenario events from Figure 1. Middle left panel: accuracy of warnings for each class of event. Correct warnings in dark blue, misclassifications by 1 or 2 classes in pale blue and yellow, respectively. These colours correspond to the scenarios in the top panel. Middle right panel: histogram of warning times issued. Bottom panels: Distribution of warning times as a function of magnitude and epicentral distance.

ure 2. Aspects of the performance of the system are also illustrated in the figure (see the caption for explanation).

The table below shows how the system performance improves with increasing number of stations. It also compares the cost functions of systems designed separately for Bishkek and Almaty, and a combined system. For different total station numbers (n) the costs of most efficient systems designed for each city dividing the available stations equally is compared to the cost of the most efficient combined system.

\begin{tabular}{ccccc}
\hline $\mathrm{n}$ & $\begin{array}{c}\text { Lowest } \\
\text { cost } \\
\text { Bishkek } \\
(\mathrm{n} / 2)\end{array}$ & $\begin{array}{c}\text { Lowest } \\
\text { cost } \\
\text { Almaty } \\
(\mathrm{n} / 2)\end{array}$ & $\begin{array}{c}\text { Sum } \\
\text { of cost } \\
\text { of separate } \\
\text { systems }\end{array}$ & $\begin{array}{c}\text { Cost of } \\
\text { combined } \\
\text { system } \\
(\mathrm{n})\end{array}$ \\
\hline 8 & 0.4491 & 0.4600 & 0.9091 & 0.8617 \\
10 & 0.4163 & 0.4410 & 0.8573 & 0.8270 \\
12 & 0.3260 & 0.3163 & 0.6423 & 0.8157 \\
14 & 0.3168 & 0.3050 & 0.6218 & 0.7822 \\
16 & 0.2754 & 0.2860 & 0.5614 & 0.7265 \\
\hline
\end{tabular}

\section{Discussion}

From the table it is clear that for network designed for a single target there is significant improvement in performance when station number is increased beyond 5 , thereafter the improvement is more gradual. Another interesting result is that if more than 5 stations per target are available, it is more efficient to construct separate warning systems for each target than to attempt a multi-target system. A possible explanation for this is that when a system attempts to protect two cities by placing stations near each one, events close to one target will trigger the alarm in both, which is likely to be a misclassified warning level for the farther target.

The result above has significant implications for a prospective regional warning system for the entire Central Asia region. As attempts to combine stations for more than one target city impair the system performance, any multi-target system would need to be made up of individual sub-networks, each designed for a specific target. An advantage of such a system would be that when an additional city or target is to be included into an operational network, existing stations and systems would not need to be manipulated. Here we show how a possible EEW system could look like for 5 target cities: Bishkek, Osh (both Kyrgyzstan), Almaty (Kazakhstan), Dushanbe (Tajikistan) and Tashkent (Uzbekistan). For this large scale system, 700 scenario events were used, again computed from tectonic maps and his- 


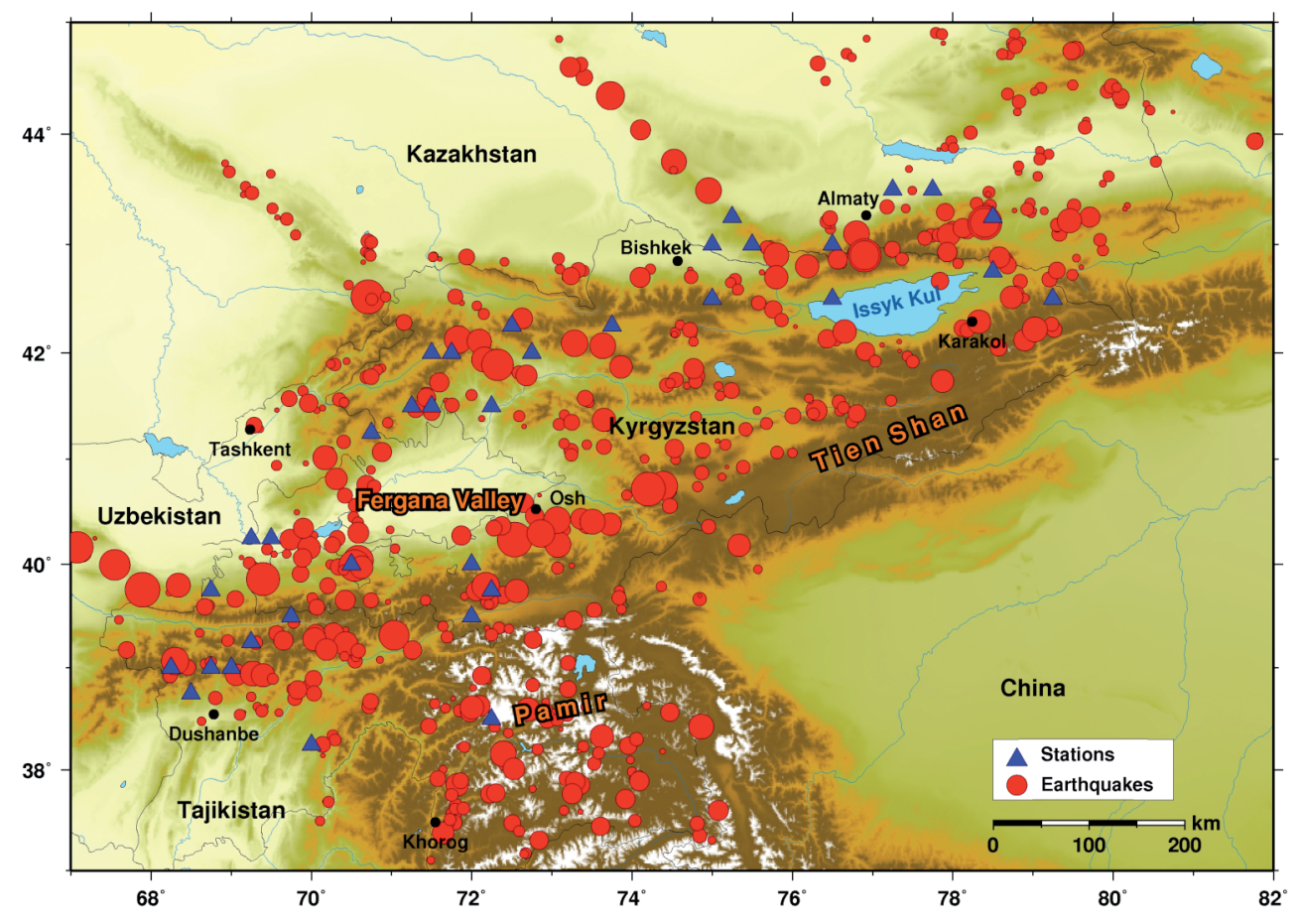

Figure 3. A proposed multi-target regional EEW system for Central Asia.

torical records, with a small random component. Figure 3 shows the location of these scenarios, as well as locations of the 35 stations making up the system of efficient 7 station networks for each of the target cities.

\section{Conclusions}

This study has demonstrated the feasibility of Earthquake Warning Systems in Central Asia. It has been demonstrated that regional warning systems are most efficient when they are designed to protect a single, clearly defined target, such a particular city. A largescale system to protect multiple targets should thus ideally consist of individual single-target subsystems. We present an example of what such a system could look like. These results will be considered when designing the new real-time strong motion network for Central Asia in the framework of the GFZ initiative ACROSS. In fact, this network, that will be installed in the time frame 2014-2017, is aimed at both reducing the endemic lack of strong motion data in Central Asia that is limiting the possibility of improving seismic hazard assessment, and at providing the first regional earthquake early warning system in the area.

Acknowledgements. This study has been supported by the EMCA and ACROSS projects, and by the Fonds National de la Recherche, Luxembourg.

\section{References}

Abdrakhmatov, K., H.-B. Havenith, D. Delvaux, D. Jongmans and P. Trefois (2003). Probabilistic PGA and arias intensity maps of Kyrgyzstan (Central
Asia), J. Seismol., 7, 203-220.

Allen, R.M., P. Gasparini, O. Kamigaichi and M. Böse (2009). The status of earthquake warning around the world: an introductory overview, Seismol. Res. Lett., 80 (5), 682-693.

Bindi, D., M. Mayfield, S. Parolai, S. Tyagunov, U.T. Begaliev and K. Abdrakhmatov (2011a). Towards an improved seismic risk scenario for Bishkek, Kyrgyz Republic, Soil Dyn. Earthq. Eng., 31, 521-525.

Bindi, D., S. Parolai, A. Oth, K. Abdrakhmatov, A. Muraliev and J. Zschau (2011b). Intensity prediction equations for Central Asia, Geophys. J. Int., 187, 327-337.

Boore, D.M. (2009). Comparing stochastic point-source and finite-source ground-motion simulations: SMSIM and EXSIM, B. Seismol. Soc. Am., 99 (6), 3202-3216.

Kalmetieva, Z.A., A.V. Mikolaichuk, B.D. Moldobekov, A.V. Meleshko, M.M. Jantaev and A.V. Zubovich (2009). Atlas of Earthquakes in Kyrgyzstan, Central Asian Institute for Applied Geoscience, Bishkek, ISBN 978-9967-25-829-7.

Krishnakumar, K. (1989). Micro-genetic algorithms for stationary and non-stationary function optimization, In: Proceedings of SPIE: Intelligent Control and Adaptive Systems, vol. 1196, Philadelphia, 289-296.

Nakamura, Y., J. Saita and T. Sato (2011). On an earthquake early warning system (EEW) and its applications, Soil Dyn. Earthq. Eng., 31, 127-136.

Oth, A., M. Böse, F. Wenzel, N. Köhler and M. Erdik (2010). Evaluation and optimization of seismic networks and algorithms for earthquake early warning - the case of Istanbul (Turkey), J. Geophys. Res., 115, 
B10311.

Picozzi, M., D. Bindi, M. Pittore, K. Kieling and S. Parolai (2013). Real-time risk assessment in seismic early warning and rapid response: a feasibility study in Bishkek (Kyrgyzstan), J. Seismol, 17, 485-505.

Pilz, M., D. Bindi, T. Boxberger, F. Hakimov, B. Moldobekov, S. Murodkulov, S. Orunbaev, M. Pittore, J. Stankiewicz, S. Ullah, F. Verjee, M. Wieland, P. Yasunov and S. Parolai (2013). First steps toward a reassessment of seismic risk of the city of Dushanbe (Tajikistan), Seismol. Res. Lett., 84 (6), 1026-1038.

Pittore, M., D. Bindi, J. Stankiewicz, A. Oth, M. Wieland, T. Boxberger and S. Parolai (2014). Towards a Lossdriven Earthquake Early Warning and Rapid Response system for Kyrgyzstan (Central Asia), Seismol. Res. Lett., 85 (6), 1328-1340; doi:10.1785 / 0220140106.

Satriano, C., Y.-M. Wu, A. Zollo and H. Kanamori (2011). Earthquake Early Warning: concepts, methods and physical grounds, Soil Dyn. Earthq. Eng., 31, 106-118.

Stankiewicz, J., D. Bindi, A. Oth and S. Parolai (2013). Designing efficient earthquake early warning systems: case study of Almaty, Kazakhstan, J. Seismol., 17, 1125-1137.

Torizin, J., G. Jentzch, P. Malischewsky, J. Kley, N. Abakanov and A. Kurskeev (2009). Rating of seismicity and reconstruction of the fault geometries in northern Tien shan within the project "Seismic Hazard Assessment for Almaty”, J. Geodyn., 48, 269-278.

\footnotetext{
^Corresponding author: Jacek Stankiewicz,

European Center for Geodynamics and Seismology, Walferdange, Luxembourg; email: jacek@ecgs.lu.

(C) 2015 by the Istituto Nazionale di Geofisica e Vulcanologia. All rights reserved.
} 